\title{
MONITORING OF CONGENITAL ANOMALIES IN LATVIA
}

\author{
Irisa Zīle ${ }^{1,2}$, Anita Villeruša', Mika Gissler ${ }^{3,4}$ \\ 'Department of Public Health and Epidemiology, Riga Stradin's University, Riga, Latvia \\ 2Department of Research, Statistics and Health Promotion, Centre for Disease Prevention and Control of Latvia, Riga, Latvia \\ ${ }^{3} \mathrm{THL}$ National Institute for Health and Welfare, Helsinki, Finland \\ ${ }^{4} \mathrm{NHV}$ Nordic School of Public Health, Gothenburg, Sweden
}

\section{SUMMARY}

Objective: This study provides a description and analysis of characteristics of the monitoring system for congenital anomalies at birth and prevalence trends in Latvia using retrospective analysis of congenital anomalies at birth with cross-sectional data on prevalence (national data from Latvia, 2000-2010).

Methods: There are three main monitoring systems on congenital anomalies among newborns and infants: the Medical Birth Register with data on live births with one or more congenital anomalies at birth, the Register on Congenital Anomalies with genetically approved cases for live births and the National Causes of Death Register with data on stillbirths. Methodological problems were analysed by calculating different prevalence rates. The main outcome measures are as follows: prevalence rate, live birth prevalence rate, major congenital anomalies live birth prevalence rate, and stillbirth rate.

Results: The live birth period prevalence was 319.7/10,000 live births, and the major congenital anomalies live birth prevalence was 211.4/10,000. The period total prevalence rate of births was $323.7 / 10,000$ live births and stillbirths. The stillbirth rate due to congenital anomalies was $6.1 / 10,000$ live and stillbirths. The live birth prevalence with congenital anomalies decreased slightly from the year 2000 to the year 2010.

Conclusions: The present system of congenital anomaly registration requires improvements for better completeness. Latvia should use the experience of Nordic countries and introduce a mother's and children's identification number to the Medical Birth Register. It would be helpful to link the information from hospitals and perinatal centres together to validate the congenital anomaly diagnoses of newborns after their discharge from the maternity unit. The monitoring system should also include information on pregnancies with congenital anomalies which do not end in birth, especially terminations of pregnancy.

Key words: monitoring system, Medical Birth Register, congenital anomalies at birth, prevalence

Address for correspondence: I. Zīle, Department of Public Health and Epidemiology, Riga Stradin's University, Dzirciema St. 16, Riga, LV-1007, Latvia. E-mail: irisa.zile@spkc.gov.lv

\section{INTRODUCTION}

Public health policies have recognised the necessity to improve the health of mothers and infants as one of the important tasks at both national and international levels worldwide. One of the tasks of the public health system is to collect data that can be used for monitoring birth defects, performing genetic and epidemiological studies as well as developing and evaluating prevention programmes. Therefore, networks of registries for the surveillance of birth defects have been established in different parts of the world. In many countries registries are the only source of information, enabling the planning of medical treatment and the prevention of congenital anomalies (1-4).

Statistical data in Europe indicate that $2-3 \%$ of newborns have at least one major congenital anomaly at birth. Congenital anomalies are an important cause of foetal, neonatal and child mortality and morbidity (1-5), accounting for 25-30\% of infant deaths in Latvia (6). A birth defect is defined as any abnormality affecting the structure or function of the body that is present from birth $(7,8)$.

The European Surveillance of Congenital Anomalies (EUROCAT) is a network providing standardized epidemiological information on congenital anomalies in Europe. EUROCAT member registries collect data from multiple sources on all major structural, congenital and chromosomal anomalies (1-3).

However, it should be mentioned that EUROCAT total prevalence rates of congenital anomalies include cases of live births, stillbirths, and the terminations of pregnancy for foetal anomalies (1).

Epidemiological studies on congenital anomalies are limited because they require the analysis of large populations and valid data with well-organised and comparable diagnostics. The completeness of registration and the validity of coding vary by country and may also vary by time $(1,4,9-13)$. Geographic and socioeconomic differences in the prevalence of congenital anomalies have been reported within European and other countries. A variation in the distributions of risk and protective factors affecting total prevalence as well as an additional variation in the prenatal detection and termination of pregnancy rates affect the prevalence and contribute to the observed variations $(1,4,9,12,14)$.

The improvement of mother and child health as well as the reduction of infant mortality is one of many goals of the public health policy "Public Health Strategy for 2011-2017" in Latvia. The general situation regarding the health of mothers and children 
in Latvia and the main risk factors are described in the Strategy (15). It is possible to obtain information on congenital anomalies present at birth among newborns in Latvia from three registries: the Medical Birth Register (MBR), the National Causes of Death Register (NCDR) and the Congenital Anomaly Register (CAR). The aim of this study is to examine the contemporary monitoring system for congenital anomalies at birth in Latvia and provide the prevalence rates with congenital anomalies at birth in the period from 2000 until 2010.

\section{MATERIALS AND METHODS}

\section{Source of Data}

Retrospective and cross-sectional cohort analyses about the period from 2000 to 2010 were performed by obtaining data from nationwide, population-based registers that were inter-linked: MBR which includes basic information on the prevalence of congenital anomalies at birth, NCDR and CAR.

The International Statistical Classification of Diseases and Related Health Problems, Tenth Revision (ICD-10), includes birth defects in Chapter XVII: Congenital malformations, deformations and chromosomal abnormalities with codes (Q00-Q99).

MBR was established in 1996. Electronic data was available since 2000, and it has been based on the information recorded in the cards issued for newborns by maternity units across the country. All congenital anomalies at birth in this registry were diagnosed during the time spent in the maternity unit (usually up to the fourth day) by ultrasound examinations and the inspection of neonatalogists.

MBR contains information that is essential for epidemiological studies and surveys on perinatal health, including data on all newborns and their characteristics (for example sex, weight, length, gestational age, Apgar score as well as the diagnosis of congenital anomalies at birth and the cause of death, wherever appropriate); the mother's socio-demographic factors (for example age, education level, nationality); factors affecting the mother's health (diseases, inimical conditions and health problems during pregnancy) and the delivery (the type of delivery, complications). MBR is obligatory and covers all national data.

The information regarding stillbirths and infant deaths up to one year of age is available from NCDR, established in 1996. This registry is obligatory and covers all deaths cases in the country. Autopsies are performed for $99 \%$ of foetal deaths and $84 \%$ of infant deaths to confirm or exclude malformation. The registry data include personal information (sex, age, birth weight as well as birth and death data), diagnoses of the cause of death, and other factors related to death. The information is retrieved from death certificates for stillbirths and infant deaths.

CAR was established in 1994 in accordance with the congenital anomalies EUROCAT registry requirements. The computer programme of the Register, donated by the Dutch EUROCAT branches, was identical to the EUROCAT computer programme. The register worked more actively in the 1990s, but less actively and on voluntary basis during the last ten years. There is complete information available on chromosomal abnormalities, such as Down's syndrome. It is connected to the women prenatal screening for foetal chromosomal abnormalities risk group in the Genet- ics Centre located in Riga, the capital of Latvia. All the necessary examinations (ultrasound screening, biochemical tests etc.) due to pregnancy are regulated by the Rules of the Cabinet of Ministers No. 611 "Procedures for Assistance with Deliveries" (16).

Since 2008 the Register on Congenital Anomalies has been a part of the Register of Patients Suffering from Certain Diseases that includes separate registers (such as the Diabetes Register, Register of Patients Suffering from Mental Diseases, Alcohol Abuse, Trauma Register etc.), which are technically linked into one data system.

\section{Statistical Analysis}

A total of congenital anomalies at birth and stillbirth rate with congenital anomalies as well as the live birth prevalence rate and rate of major congenital anomalies at birth were calculated. Terminations of pregnancies due to congenital anomalies were not included in the prevalence calculation.

In MBR the diagnoses are classified according to ICD-10. These diagnosis codes were correspondingly regrouped in cases of major congenital anomalies at birth, adapting the methodology of EUROCAT (17).

Major congenital anomalies were defined as lethal (if the defects cause stillbirth; infant death or pregnancies are terminated after the prenatal diagnosis) and severe (if the defects without medical intervention cause handicap or death) defects altogether (18).

The information from the CAR database was used in the data analysis to characterise the registration of congenital anomalies at birth and assess the completeness of MBR data. The intercomparison of diagnoses was based on 587 records pooled from CAR, using the available record linkage with MBR. Also within the framework of this analysis, the diagnoses of congenital anomalies were grouped in compliance with the EUROCAT major congenital anomaly subgroups.

The interrelated comparison of congenital anomaly coverage and correspondence of diagnoses within the data analysis (MBR vs CAR) was carried out with the help of calculations made applying the methodology used by Danish researchers (19). The coincidence of diagnoses or positive registered cases equals the number of newborns correctly diagnosed with congenital anomaly at birth in MBR. The coverage of congenital anomaly cases at birth or completeness equals the number of newborns with correctly diagnosed or unspecified congenital anomaly at birth in MBR.

This study was approved by the Ethics Committee of Riga Stradin's University on 21 January 2011.

\section{Calculation of Prevalence}

Total prevalence of congenital anomalies at birth: the number of live births and stillbirths (stillbirths after 22nd week of pregnancy and with birth weight 500 grams) with congenital anomalies per 10,000 births.

Live births prevalence of congenital anomalies at birth: the number of live births having congenital anomalies per 10,000 live births.

Live births prevalence of major congenital anomalies at birth: the number of live births having major congenital anomalies (according to ICD-10 by EUROCAT methodology) per 10,000 live births. 
Stillbirths with congenital anomalies: the number of stillbirths (stillbirths after 22nd week of pregnancy and with birth weight $500 \mathrm{~g}$ ) having congenital anomalies per 10,000 live births and stillbirths.

\section{RESULTS}

A total of congenital anomalies at birth prevalence rate was 323.7 (95\% CI 317.5-330.9) per 10,000 live births and stillbirths (2000-2010) with the annual decrease of 9.3 cases per 10,000 live and stillbirths $(\mathrm{p}<0.05)$.

A total of 7,451 live-born children had at least one congenital anomaly at birth (2000-2010) out of which $66.1 \%(n=4,927)$ had at least one major congenital anomaly related to serious defects for a newborn. These data were obtained from MBR, based on the information provided in newborn cards issued by a maternity hospital or unit.

The data on live-born newborns with congenital anomalies at birth from MBR gave live birth period prevalence of 319.7 (95\% CI 286.5-354.0) per 10,000 live births. The live birth prevalence with congenital anomalies slightly decreased from the year 2000 to the year 2010. The average decrease by linear regression was 8.8 cases per 10,000 live births per year $(p>0.05)$. The period prevalence of major congenital anomalies at birth among live births was 211.4/10,000 (95\% CI 197.4-226.2). Overall, major congenital anomalies prevalence rate has a statistically significant decrease - on average by $5.2 / 10,000$ during the years $(\mathrm{p}<0.01)$ (Fig. 1.).

Data on stillbirths can be retrieved from NCDR. From 2000-2010, there were 1,531 foetal deaths reported, with the average of $9.3 \%(n=143)$ stillbirths due to congenital anomalies and registered as the main cause of death by NCDR. The stillbirth rate due to congenital anomalies was 6.1 (per 10,000 live and stillbirths).

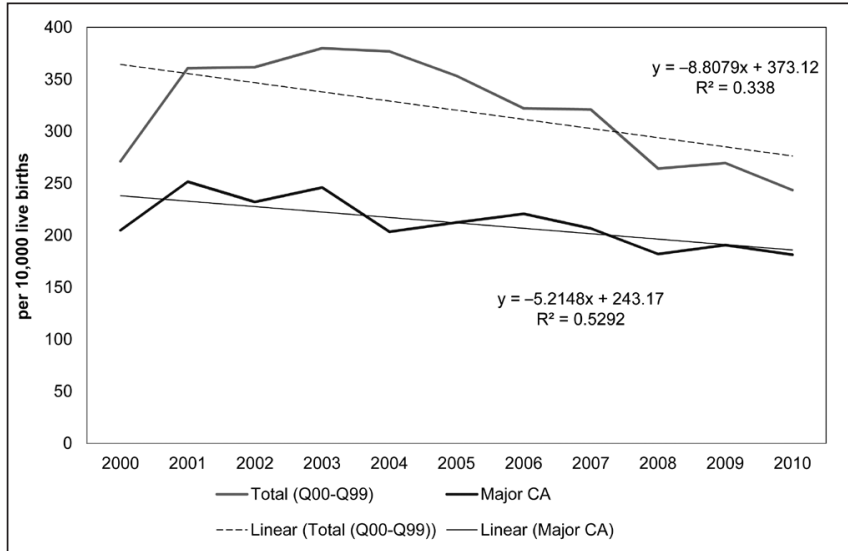

Fig. 1. Trends in the live births prevalence of congenital anomalies at birth from 2000 to 2010, per 10,000 live births (data source - Medical Birth Register).

Table 1 displays the cases and prevalence of live births and stillbirths with congenital anomalies at birth from MBR and NCDR in Latvia.

The coverage analysis of congenital anomaly registration at birth among live births included 587 cases (2000-2010) provided by MBR in relation to CAR. It was possible to link both registration systems as there was $33.2 \%$ of information available to identify a particular person.

The coincidence of diagnoses or the number of properly registered cases in MBR accounted for $53.8 \%$ of cases $(95 \% \mathrm{CI}$ 49.8-57.8) (Fig. 2.).

The evaluation of completeness of the registered cases in MBR in comparison to CAR has showed that it comprises $68.2 \%$ of cases (95\% CI 65.0-72.4). The highest share of diagnosis coincidence and more complete registration at birth institutions is related to visual congenital defects, such as cleft lip and cleft palate (61.0\%; 95\% CI 50.2-70.8) as well as limb anomalies (76.6\%;

Table 1. Cases and prevalence (per 10,000) of congenital anomalies (Q00-Q99) in Latvia (2000-2010) (data sources - Medical Birth Register and National Causes of Death Register)

\begin{tabular}{|l|c|c|c|c|c|c|c|}
\hline Year & $\begin{array}{c}\text { Live birth } \\
\text { (n) }\end{array}$ & $\begin{array}{c}\text { Foetal death } \\
\text { (n) }\end{array}$ & $\begin{array}{c}\text { Live birth } \\
\text { with major CA } \\
\text { (n) }\end{array}$ & $\begin{array}{c}\text { Live birth } \\
\text { prevalence } \\
\text { rate* }\end{array}$ & $\begin{array}{c}\text { Major CA live } \\
\text { birth } \\
\text { prevalence } \\
\text { rate* }\end{array}$ & $\begin{array}{c}\text { Stillbirth rate } \\
\text { with CA** }\end{array}$ & $\begin{array}{c}\text { Total CA } \\
\text { prevalence at } \\
\text { birth (live and } \\
\text { stillbirths) }\end{array}$ \\
\hline 2000 & 548 & 26 & 414 & 271.1 & 204.8 & 12.8 & 281.8 \\
\hline 2001 & 707 & 20 & 493 & 360.6 & 251.5 & 10.1 & 368.2 \\
\hline 2002 & 723 & 13 & 464 & 361.6 & 232.0 & 6.4 & 364.9 \\
\hline 2003 & 797 & 11 & 516 & 379.8 & 245.9 & 5.2 & 382.7 \\
\hline 2004 & 767 & 5 & 414 & 376.8 & 203.4 & 2.4 & 376.7 \\
\hline 2005 & 761 & 14 & 457 & 353.3 & 212.2 & 6.5 & 357.6 \\
\hline 2006 & 718 & 11 & 492 & 322.0 & 220.6 & 4.9 & 324.7 \\
\hline 2007 & 747 & 11 & 481 & 320.9 & 206.6 & 4.7 & 323.9 \\
\hline 2008 & 633 & 12 & 436 & 264.1 & 181.9 & 5.0 & 267.4 \\
\hline 2009 & 584 & 14 & 413 & 269.4 & 190.5 & 6.4 & 274.2 \\
\hline 2010 & 466 & 6 & 347 & 243.4 & 181.2 & 3.1 & 245.1 \\
\hline Total & 7,451 & 143 & 4,927 & 319.7 & 211.4 & 6.1 & 323.7 \\
\hline
\end{tabular}

$\mathrm{n}$ - number, CA - congenital anomalies,

*per 10,000 live births, ** per 10,000 live and stillbirths 


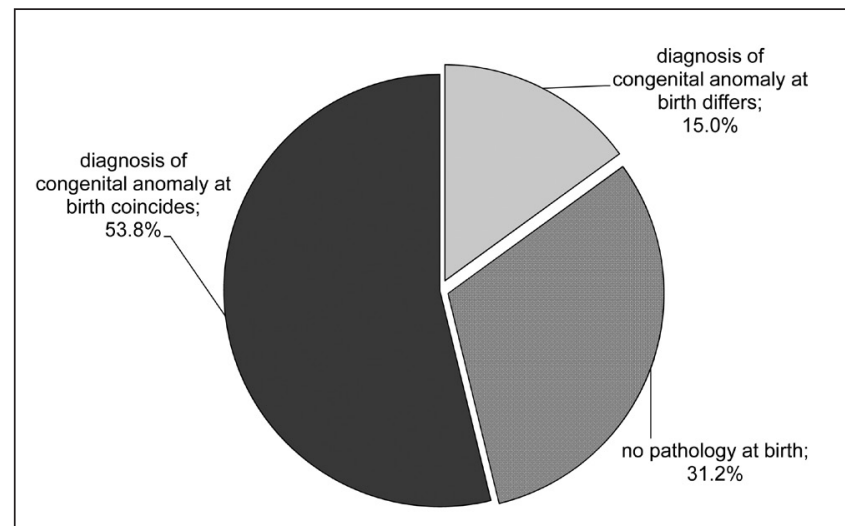

Fig. 2. Coverage of live born congenital anomalies at birth institutions (MBR) in comparison with the Congenital Anomaly Register (2000-2010), \%.

95\% CI 62.8-86.4). Congenital heart defects (37.5\%; 95\% CI 26.7-49.7) have the lowest share in diagnosis coverage in MBR.

\section{DISCUSSION}

Our aim is to describe the congenital anomaly monitoring system using data from various information sources and to analyse the prevalence and stillbirth rates of congenital anomalies at birth. The prevalence for the whole time period is calculated for all Q diagnosis group (ICD-10; Q00-Q99), as well as the prevalence for all major congenital anomalies at birth. The timely (prenatal) diagnosis of life threating and other major congenital anomalies plays an important role in decision-making process on the termination of pregnancy done by pregnant women. Moreover, it helps to ensure appropriate obstetrical and neonatal care to the condition of a foetus and, if necessary, emergency surgical treatment.

Currently, Latvia does not have unified or compatible databases that register congenital anomalies, so there is no reliable estimate for the total prevalence of congenital anomalies to apply for analyses and comparisons.

The data of congenital anomaly monitoring system show that in Europe the average period (2000-2004) prevalence rate for liveborn comprises 199.3/10,000 (1), whereas the period (2000-2010) prevalence rate in Latvia is slightly higher -211.4 per 10,000 live births. The evaluation of a five-year period (2000-2004) shows that in Latvia the prevalence of major congenital anomalies among newborn, if compared to the EUROCAT average prevalence, is even higher - 227.5/10,000. A relatively larger occurrence may be explained with more frequent prevalence of congenital anomalies among newborns or with overdiagnosing of cases in birth institutions as the diagnoses are not supplemented, validated, or changed after the data are sent to MBR.

The information on congenital anomalies from MBR does not include information about cases that are discovered later, after the newborns are discharged from the maternity unit. Moreover, the diagnoses made in maternity units are not specified later for recording in MBR, and there is no feedback from hospitals and perinatal care centres. In some cases, there may be over-reporting because the diagnosis made in the maternity units is not always confirmed by a laboratory.
The analyses of data from MBR have shown that the live birth prevalence of total and major congenital anomalies in newborns decreased from the year 2000 to 2010 . This can partly be explained by increased prenatal screening and increasing numbers of terminations of pregnancy due to congenital anomalies. Unfortunately, such detailed information on prenatal screening is not available in Latvia. However, statistical data show that on average $88 \%$ of pregnant women of Latvia have an ultrasound examination, but prenatally diagnosed cases of anomalies are relatively low. For example, in the case of gastroschisis $76.5 \%$ had undergone prenatal ultrasound, but only $29.4 \%$ of cases were prenatally detected; in the case of omphalocele $89.3 \%$ had undergone prenatal ultrasound and 3.6\% were prenatally detected (20). According to EUROCAT, on average the rates of prenatally diagnosis cases are rather high in Europe, e.g. in relation to gastroschisis - 95\%; spina bifida $-81 \%$; Down's syndrome $-72 \%$ (8).

Furthermore, a new policy and action plan have been introduced in Latvia - "Plan for Improving Mother and Child Heath for 2012-2014" that provide changes related to the prenatal diagnostics and requires additional medical examinations for pregnant women, including ultrasound screening and necessary tests to facilitate timely diagnostics of congenital anomalies $(16,21)$.

A decreasing tendency in the total of prevalence rate of congenital anomalies is also observed in WHO and EUROCAT data, which is mainly explained by the better antenatal care and improved management of known risk factors such as maternal chronic health conditions e.g. diabetes, and the reduction of health risk behaviours e.g. smoking $(1,22,23)$.

The data on congenital anomalies from MBR have not been widely used before. Since 2010, MBR can be linked to the Register of Patients Suffering from Certain Diseases, also including the Register of Congenital Anomalies. This unified information system will make the compilation of more reliable data feasible, and enable the analysis and comparisons of these data in a much broader way. However, different requirements have to be fulfilled to improve the completeness, quality and storage of the health information system in Latvia. Currently, the improvement and restoration of the registry system is ongoing in order to provide the necessary records to the system. The e-Health collaboration platform pilot project has been designed as the environment for an electronic exchange of information between different health information systems. In the future, these new data could be available for public health surveillance and epidemiological studies on congenital anomalies, as the linkages of different datasets will become feasible. For example, studies of different risk factors, trend predictions, evaluations of the quality of health care, and assessment of the burden of disease related to congenital anomalies would be possible to improve perinatal and infant health in Latvia.

In Latvia, MBR linkage to CAR and the analysis of the coincidence of diagnoses have showed that on average $53.8 \%$ of registered diagnoses coincide. Thus, CAR contains the information on cases that are diagnosed up to one year of age. Similar results were achieved by the research carried out in Australia. When the information from the Congenial Anomaly Register of Australia was compared to the Genetic Centre and Children Hospital Patient data, $54 \%$ of cases indicated the coincidence of diagnoses (10). The assessment of congenital anomalies completeness in MBR and its linking with CAR has led to the conclusion that on average $68.2 \%$ of congenital anomalies are discovered in delivery units. 
The comparison of congenital anomalies coverage in breakdown by diagnosis groups has shown that most often maternity units register visual congenital defects, whereas the lowest coverage is related to congenital heart defects and chromosome anomalies. Furthermore, other similar studies on registration coverage have reported that most frequently data of the newborn registration and birth certificates indicate or notify those congenital defects which are more visible (24).

Nevertheless, it is difficult to assess how many pregnancies with congenital anomalies end in spontaneous abortions or terminations of pregnancy in Latvia. The lack of information significantly affects the indicators of congenital anomalies. EUROCAT provides data on the terminations of pregnancies for foetal anomalies following prenatal diagnosis $(1,8,9)$. As no complete data on the terminations of pregnancy for foetal anomalies exist in Latvia, we could not include them in our analysis. The data from routine statistics about abortions just indicate a total number of medical abortions (25). For instance, there were 293 medical abortions performed per year with an average decrease of 33 abortions $(\mathrm{p}<0.01)$ during the study period $(2000-2010)$.

Being aware that any registry of congenital anomalies usually fulfils several functions: to provide accurate data on the causes of congenital anomalies and risk assessment; to track trends and identify variations in the occurrence of congenital anomalies at birth; to evaluate preventive measures; and to provide evidence for maternal health programmes and policy development, one should pay attention to other ways of applying the data. Thus, these types of routinely collected data provide opportunities for research purposes $(1,4,11-13,26-28)$. For example, the Polish Registry of Congenital Malformations was established in 1997 as a local-level registry with a centre at the Poznan University of Medical Sciences. Today, this registry is one of the members of EUROCAT, providing statistical analyses for a representative part of the country. The information maintained in this registry has contributed to a decrease in perinatal deaths and the death of infants (29).

So far, congenital anomalies have been identified as one of the major groups of mainly rare diseases in need of concerted action across Europe. The pooling of expertise, improving of coding and classifications, surveillance, evaluation of clusters, and identification of possibilities for primary prevention are some of the goals of the EU-funded Joint Action EUROCAT 2011-2013, in which Latvia is participating as an associated partner. The results of this Joint Action are expected to have an important impact on the future policy on rare diseases nationally and at the European level (30).

The international data on congenital anomalies vary significantly due to the differences in definitions and data availability by country. Some countries produce congenital anomaly prevalence rates that include live births and stillbirths, some only include live births, whereas some also include terminated pregnancies due to foetal anomalies following prenatal diagnosis. In the database of the World Health Organisation "Health for All" (HFA) the 2010 rate of congenital anomalies was 2,455 per 100,000 live births in Latvia (data source: MBR and NCDR includes live births and stillbirths), 3,472/100,000 in Lithuania (Medical Birth Register), and 3,968/100,000 in Estonia (annual reporting, maternity hospital data (aged 0-6 days). In the Nordic countries the rates of congenital anomalies are higher as the data on terminations for birth defects and cases which are diagnosed later up to the age of one year are included: 3,904/100,000 in Finland (2009) (data source: the Register of Congenital Anomalies), 4,681/100,000 in Norway (2009) (data source gynaecological/births and paediatric departments; data includes late-term abortions); and 7,825/100,000 in Denmark (2010) (data source: The Birth Registry). The prevalence rate of congenital anomalies in Slovakia is on the same level as in Latvia - 2,518/100,000 (2010), but is also lower than in the Nordic countries (22). The Slovak registry also covers all births annually according to the reports of birth defects from delivery units (31). In Hungary, that has a higher rate than Latvia or Slovakia $-4,730 / 100,000$ (2009), prenatally diagnosed and terminated foetuses are registered as well (22).

These differences may be caused by a variation in the registration practices and other factors related to data collection that should be investigated in greater detail. The comparison of the data and monitoring systems of the Nordic and Baltic countries would be interesting for researchers and clinicians, governments and healthcare workers in the fields of public health, epidemiology and health services research. The Nordic countries are well-known worldwide for their well-established monitoring systems of medical and administrative registers and extensive data analysis capabilities related to data linkage. In order to ensure the quality of surveillance data, it is important to analyse the data to determine the relevance and applicability of the obtained information.

The analysis of different registers related to congenital anomalies has identified several challenges. The primary issue regarding multiple data systems is the difficulties in comparing incidences by area and time. Therefore, some improvements in the registry systems are urgently needed. These improvements should include better accuracy and accessibility of registry data, the possibility to link registers on congenital anomalies to the causes of death and other registries as well as the need to include terminations of pregnancy due to congenital anomalies in the surveillance system.

\section{CONCLUSIONS}

Several problems encountered in the calculations of congenital anomaly prevalence (int. al. total and at birth) show a necessity to improve the national registration system of congenital anomalies. The present system of congenital anomaly registration should be advanced for better completeness. Thus, multiple possibilities for inter-linkage would increase the usefulness of accumulated and stored information as in research as well as in practical medicine.

Latvia should use the experience of the Nordic countries and introduce a mother's and children's identification number (ID) to MBR, which would be helpful for a linkage with other registries in Latvia, data from hospitals and perinatal centres in order to include and validate congenital anomaly diagnoses at birth of newborns after their discharge from the maternity unit. Thus, the inclusion of terminations of pregnancy due to congenital anomalies in the monitoring system is essential.

To perform international comparisons it is highly important to establish a common methodology, such as definitions and inclusion/exclusion criteria. Right now, this work initiated by the EU-funded Joint Action EUROCAT 2011-2013 project has already been continued by the Centre for Disease Prevention and Control of Latvia together with the Children's Clinical University 
Hospital that will facilitate the process of data collection and validation on congenital anomalies in the near future.

\section{Acknowledgements}

This work was supported by the European Social Fund (ESF) national programme "Support for PhD programmes and post-doctoral researches", "Support to doctoral and postdoctoral research in medical science" project and the ESF project "Support for doctoral study programme and research degrees Riga Stradin's University” grant.

\section{Conflict of Interests}

None declared

\section{REFERENCES}

1. EUROCAT. Special report: the status of health in the European Union: congenital malformations [Internet]. Newtownabbey: EUROCAT; 2009 [cited 2014 Feb 25]. Available from: http://www.eurocat-network.eu/ content/Special-Report-Con-Malfs.pdf.

2. Boyd PA, Haeusler M, Barisic I, Loane M, Garne E, Dolk H. Paper 1: The EUROCAT network - organization and processes. Birth Defects Res A Clin Mol Teratol. 2011 Mar;91 Suppl 1:S2-15.

3. Barišić I; EUROCAT Working Group. EUROCAT - epidemiological surveillance of congenital anomalies in Europe. Zdrav Vestn. 2009;78 Suppl 1:175-9.

4. Christianson A, Howson CP, Modell B. March of dimes: global report on birth defects: the hidden toll of dying and disabled children. White Plains: March of Dimes Birth Defects Foundation; 2006.

5. Boyd PA, Armstrong B, Dolk H, Botting B, Pattenden S, Abramsky L, et al. Congenital anomaly surveillance in England - ascertainment deficiencies in the national system. BMJ. 2005 Jan 1;330(7481):27. doi: 10.1136/ bmj.38300.665301.3A.

6. The Centre for Disease Prevention and Control of Latvia. Statistical yearbook of health care in Latvia 2011 [Internet]. Riga: CDPC; 2012 [cited 2014 Feb 25]. Available from: http://www.spkc.gov.lv/veselibasaprupes-statistika/. (In Latvian.)

7. World Health Organization. Birth defects: report by the Secretariat. Geneva: WHO; 2010.

8. EURO-PERISTAT; SCPE; EUROCAT; EURONEOSTAT. European perinatal health report: data from 2004. EURO-PERISTAT; 2008.

9. Khoshnood B, Greenlees R, Loane M, Dolk H; EUROCAT Project Management Committee; EUROCAT Working Group. Paper 2: EUROCAT public health indicators for congenital anomalies in Europe. Birth Defects Res A Clin Mol Teratol. 2011 Mar;91 Suppl 1:S16-22.

10. Riley M, Phyland S, Halliday J. Validation study of the Victorian Birth Defects Register. J Paediatr Child Health. 2004 Sep-Oct;40(9-10):544-8.

11. Knox EG, Armstrong EH, Lancashire R. The quality of notification of congenital malformations. J Epidemiol Community Health. 1984 Dec;38(4):296-305

12. Dutton SJ, Owens JR, Harris F. Ascertainment of congenital malformations: a comparative study of two systems. J Epidemiol Community Health. 1991 Dec;45(4):294-8.

13. Misra T, Dattani N, Majeed A. Evaluation of the National Congenital Anomaly System in England and Wales. Arch Dis Child Fetal Neonatal Ed. 2005 Sep;90(5):F368-73.

14. Mai CT, Law DJ, Mason CA, McDowell BD, Meyer RE, Musa D; National Birth Defects Prevention Network. Collection, use, and protection of population-based birth defects surveillance data in the united states. Birth Defects Res A Clin Mol Teratol. 2007 Dec;79(12):811-4.
15. Public health strategy for 2011-2017: adopted by Cabinet of Ministers Order No. 504 dated 5 October 2011 [Internet]. Ministry of Health of the Republic of Latvia [cited 2014 Feb 25]. Available from: http://www. vm.gov.lv/images/userfiles/public_health_strategy_2011_2017.pdf.

16. Rules of Cabinet of Ministers No. 611. Obstetric assurance procedures. 21.08.2012. (In Latvian.)

17. EUROCAT. Malformation coding guides. Coding of EUROCAT subgroups of congenital anomalies [Internet]. Newtownabbey: EUROCAT; 2012 [cited 2014 Feb 25]. Available from: http://www.eurocat-network. eu/aboutus/datacollection/guidelinesforregistration/malformationcodingguides.

18. Czeizel AE. Birth defects are preventable. Int J Med Sci. 2005;2(3):91-2.

19. Larsen H, Nielsen GL, Bendsen J, Flint C, Olsen J, Sørensen HT. Predictive value and completeness of the registration of congenital abnormalities in three Danish population-based registries. Scand J Public Health. 2003;31(1):12-6.

20. Pētersons A, Ābola Z, Villeruša A et al. Development of algorithms based on modern technologies for diagnostics and treatment of congenital malformations of children for reduction of patient mortality, survival prolongation and improvement of life quality. In: Pīrāgs V, editor. Main diseases threatening the life expectancy and life quality of the Latvian population. Riga: 2009. p. 77-93. (In Latvian.)

21. Rules of Cabinet of Ministers No. 269. Plan for improving mother and child health for 2012-2014. 19.06.2012. (In Latvian.)

22. European Health for All Database (HFA-DB) [Internet]. Copenhagen: WHO [updated 2012; cited 2014 Feb 25]. Available from: http://data. euro.who.int/hfadb/

23. EUROCAT. EUROCAT statistical monitoring report - 2009 [Internet]. Newtownabbey: EUROCAT; 2012 [cited 2014 Feb 25]. Available from: http://ec.europa.eu/health/rare diseases/docs/eurocat stat 2009 en.pdf.

24. Honein MA, Paulozzi LJ. Birth defects surveillance: assessing the "gold standard". Am J Public Health. 1999 Aug;89(8):1238-40.

25. National Health Service. Statistical data 2010 [Internet]. Riga: National Health Service; 2011 [cited 2014 Feb 25]. Available from: http://www. vmnvd.gov.lv/lv/33-statistika/statistikas-dati-par-2010-gadu-ieklauts-arisalidzinajums-ar-ieprieksejiem-gadiem. (In Latvian.)

26. Bird TM, Hobbs CA, Cleves MA, Tilford JM, Robbins JM. National rates of birth defects among hospitalized newborns. Birth Defects Res A Clin Mol Teratol. 2006 Nov;76(11):762-9.

27. Wang Y, Caggana M, Sango-Jordan M, Sun M, Druschel CM. Long-term follow-up of children with confirmed newborn screening disorders using record linkage. Genet Med. 2011 Oct;13(10):881-6.

28. Loane M, Dolk H, Garne E, Greenlees R; EUROCAT Working Group. Paper 3: EUROCAT data quality indicators for population-based registries of congenital anomalies. Birth Defects Res A Clin Mol Teratol. 2011 Mar;91 Suppl 1:S23-30.

29. Latos-Bieleńska A, Materna-Kiryluk A; PRCM Working Group. Polish Registry of Congenital Malformations - aims and organization of the registry monitoring 300000 births a year. J Appl Genet. 2005;46(4):341-8.

30. EUROCAT. Joint Action EUROCAT 2011-2013 Funded by the Public Health Programme 2008-2013 of the European Commission [Internet]. Newtownabbey: EUROCAT [cited 2014 Feb 25]. Available from: http:// www.eurocat-network.eu/jointactioneurocat.

31. International Clearinghouse for Birth Defects Surveillance and Research. Annual Report 2011 with data for 2009 [Internet]. Roma: International Centre on Birth Defects - ICBDSR Centre [cited 2014 Feb 25]. Available from: http://www.icbdsr.org/filebank/documents/ar2005/Report2011.pdf. 